\title{
Prioritizing simple administrative measures to ensure appropriate tuberculosis infection control
}

\author{
D Chemtob \\ From International Conference on Prevention \& Infection Control (ICPIC 2011) \\ Geneva, Switzerland. 29 June - 2 July 2011
}

\section{Introduction / objectives}

For reducing Tuberculosis (TB) transmission, early diagnosis and prompt treatment of TB patients should be completed by implementing TB Infection Control (TBIC) measures. Our objective is to analyze the TB-IC Global Policy, its current implementation status and strategies to scale-up TB-IC measures at country level.

\section{Methods}

Analysis of the TB-IC Global Policy, and description of strategies and challenges for scaling-up TB-IC measures at country level.

\section{Results}

"WHO Policy on TB-IC in Health-Care Facilities, Congregate Settings and Households" (2009) recommended the implementation of a set of measures (administrative, personal protection, environmental). Since, WHO and other partners have been engaged in a series of actions, including Regional/National trainings of hundreds of professionals and Technical Assistance to countries. A new indicator for monitoring TB-IC and the cost analysis for a worldwide implementation have also been integrated into the "Global Plan to Stop TB 2011-2015". However, TB-IC is still in a preliminary implementation phase in most of the countries. Scaling-up should therefore prioritize the implementation of simple and economical administrative measures; e.g. identifying potentially infectious cases (triage), separating them, and assuring health care worker protection. By embedding TB-IC plans into broader ones (i.e. MDR-TB, HIV, Health System Strengthening, general IC), TB-IC measures should progressively be incorporated into national plans funded by major donors. Preliminary data on

Stop TB Department, World Health Organization, Geneva, Switzerland country implementation, opportunities and bottle-necks will be presented.

\section{Conclusion}

Using first simple and economical TB-IC measures, together with embedding TB-IC within broader plans, should contribute to their step-wise implementation. This should also ultimately impact positively the country TB burden.

\section{Disclosure of interest}

None declared.

Published: 29 June 2011

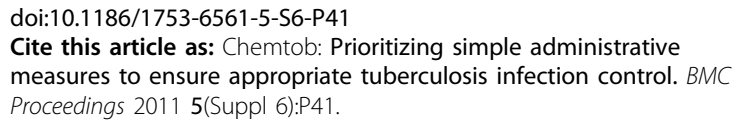

Submit your next manuscript to BioMed Central and take full advantage of:

- Convenient online submission

- Thorough peer review

- No space constraints or color figure charges

- Immediate publication on acceptance

- Inclusion in PubMed, CAS, Scopus and Google Scholar

- Research which is freely available for redistribution 